\title{
PC/PLC Based Simultaneous Running of More than One Laboratory Experiments Using WxPython and Pymodbus
}

\author{
Jawad Radhi Mahmood ${ }^{1}$, Ramzy Salim Ali $^{2}$ \\ \{jawad.mahmood@uobasrah.edu.iq ${ }^{1}$,ramzy.ali@uobasrah.edu.iq ${ }^{2}$ \} \\ Department of Electrical Engineering, College of Engineering, University of Basrah, Basrah 610001, \\ Iraq $^{1}$ \\ Department of Electrical Engineering, College of Engineering, University of Basrah, Basrah 610001, \\ Iraq $^{2}$
}

\begin{abstract}
The Programmable Logic Controllers (PLCs) allow many industrial fields to input and output devices to be connected directly to their input and output points or modules. They also allow communication with more than one device through their communication ports. For these issues, the PLCs can be used to play an important role in supporting the education process. In this context, this paper introduces PC/PLC based laboratory platform to allow the simultaneous utilization of three experimental setups, one for Direct-On-Line (DOL) and star/delta starting of three-phase induction motor, one for the single-phase AC line controller, and one for the Inverse-Definite-Minimum-Time (IDMT) overcurrent protective relay. The first one allows the user to monitor and record the three-phase induction motor's current history under DOL and star/delta starting methods. The second one allows its user to understand the difference between the magnetic relay and Solid-State-Relay (SSR), run the AC line controller in ON/OFF, phase angle, and integral cycle modes of operations, and understand the basic construction and operation of soft starters. With the third setup, the user can test the various standard characteristic curves of the IDMT overcurrent relay. This platform uses three Personal Computers (PCs) and one Programmable Logic Controller (PLC). Each PC uses Wxpython (Graphic user interface toolkit of python programming language) and PyModbus communication utility to interface its related set-up to the central PLC.
\end{abstract}

Keywords: Direct-On-Line DOL, Solid-State-Relay (SSR), Programmable Logic Controller (PLC); WxPython; Pymodbus.

\section{Introduction}

An accurate account of engineering practice could help educators explain the relevance of coursework to students, helping to provide appropriate motivation for learning [1]. On the level of universities, the engineering practice could, to some extent, be achieved through instructional laboratories which form an essential part of the engineering curricula [2]. They allow students to engage with real hardware, components, material and validates their conceptual knowledge, and learn from trial and error [3]. They provide practical knowledge that goes beyond the mere theory[4]. In general, Most lecturers feel that laboratory work helps to develop personal skills [5]. From this satisfaction and understanding, some attempts have been done to develop engineering laboratories in engineering universities and colleges. As an example of these attempts, Yousif I. AlMashhadany[ 6] introduced programable logic controller-based platform for classical control laboratory. J.M. Fernandes \& T. Van Niekerk [7] introduced a programmable logic controller-based laboratory for nonlinear systems (ball-on-wheel balancing 
system). Mahmood et.al. [8] developed a PLC-HMI driven platform to control the speed of a three-phase induction motor using a fuzzy logic controller and the traditional ProportionalIntegral-Derivative (PID) controller. Gerard Geaney and Tom O'Mahoney[9] introduced a remote laboratory for PLC education by using three PLCs (S7-1200 as a master PLC to allow the student to select either S7200 or Micrologic 1000 analog for programming). O "zgu" r Cemal $\mathrm{O}{ }^{*}$ zerdem [10], Introduced two experimental setups using PLC (one for the elevator and the second for metal ball carrier). Luiz F Alves, Dennis Brand, and An Oliveira [11] discussed the use of a plant driven by four PLCs and allows the simultaneous running of three setups (water temperature in the plant, water level in two reservoirs, and water flow rate through the plant). Mahmood et al. [12] also presented a PLC/HMI-based real-time educational power system protective relay platform, to facilitate the understanding of the operating principle of the Inverse Definite-Minimum-Time relays (IDMT).

The current paper introduces an educational platform that allows the simultaneous utilization of three instructional setups through the cooperation of two computational platforms (the personal computer and the programmable logic controller) with the help of the well known Python programming language and its Wxpython graphic user interface kit and Pymodbus utility which is a full Modbus protocol implementation.

The Programmable logic controller (PLC) is a computer-based, solid-state, single-processor device[13]. It can accept digital and analog input and output signals coming from the industrial field input and output devices. PLC comes with built-in communication ports usually 9-pin RS232, RS-422, RS-485, and Ethernet [14]. PLC supports more than one operation mode, the repetitive or scan mode of operation which has been adopted in this work is the main operation mode that each PLC should have at least one of it. In this mode, the user application program is repetitively executed from its start statement to its end statement as long as the PLC is in the run mode. Here the program execution does not depend upon any condition. From the point of view of programming languages, all the PLCs support ladder language, and some of them in addition to the ladder language support function block and /or structured text programming languages. In this work, the structured text programming language has been used. This language is very close to the well-known Pascal language.

Wxpython is a cross-platform python programming language. Its library allows programmers to develop highly Graphical User Interfaces (GUI) for their programs using Menu bars, Menus, Panels, StaticText, TextCtrl, RedioItem, CheckItem, Button, ToggleButton, ComboBox, etc. In WxPython all the elements of a GUI are contained within top-level windows such as wx.Frame or wx.Dialog [15].

Modbus protocol is widely used in the industrial field. It supports client/server communication between field devices such as PLCs, VFDs, and smart input/output units. Modbus devices are provided with well defined Modbus memory map. Pymodbus is a full Modbus protocol implementation. It uses asynchronous communication over TCP/IP connections [16]. It allows reading of data from PLCs and writing data to PLCs over Ethernet connection[17]. The PLCs data can be accessed as bit(s) and word(s).

\section{The Work Aim}

Most of the students feel there is a gap between theory and practice and this untrue feeling hurts their cooperation with the teaching staff. So, to alleviate or eliminate this untrue feeling, 
the teachers should show their students the concrete relationship between theory and practice through experimental work.

The present work aims to achieve the above target and increase the engineering teaching process efficiency through integrating what is explained in the classroom with the real-time behaviour of the covered items or topics.

\section{The Proposed Platform Architecture}

The proposed platform architecture consists of two parts. These are the hardware and the software parts.

\subsection{The Hardware Part}

As stated above, the proposed work supports the simultaneous running of three experiments. The details of this structure are shown in Fig 1 and Fig 2, where Fig 1 introduces the general layout, and Fig 2 details the wiring of each setup and its relation with the PLC input and output points.

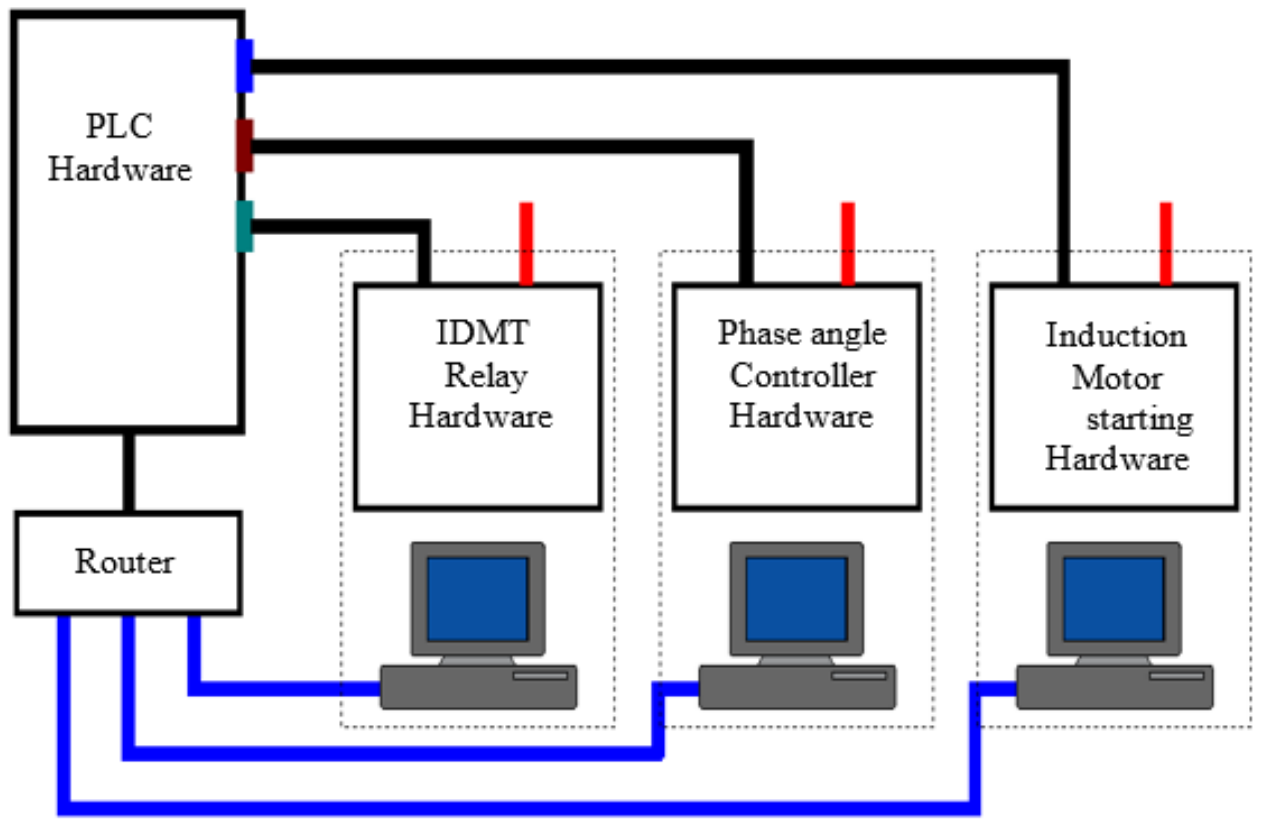

Fig 1. Hardware Setup. 


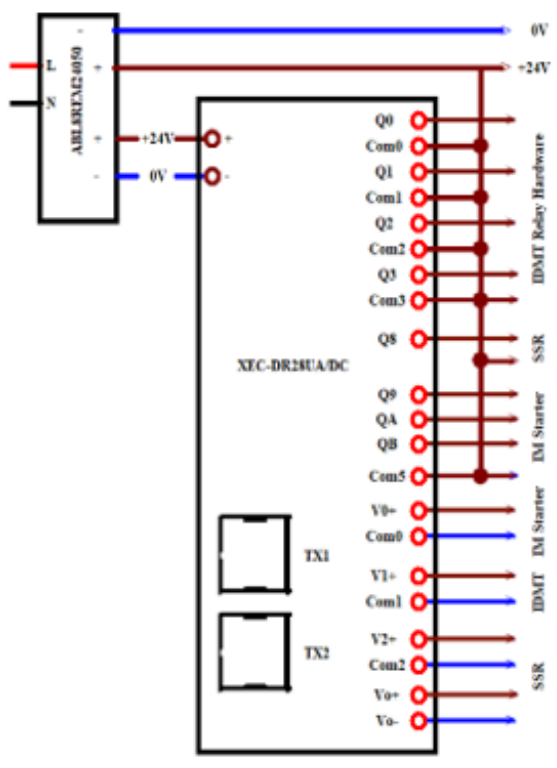

(a)

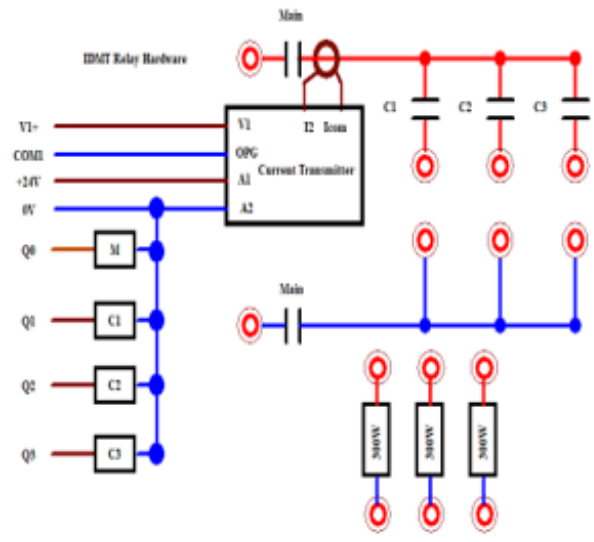

(c)

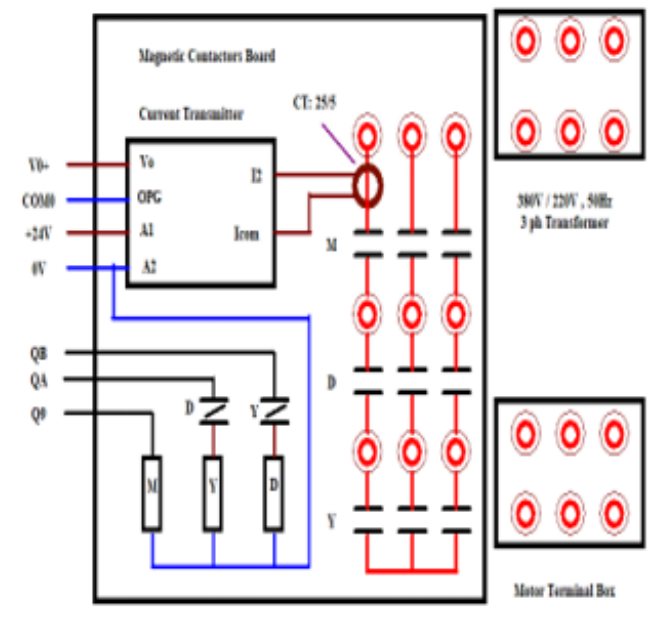

(b)

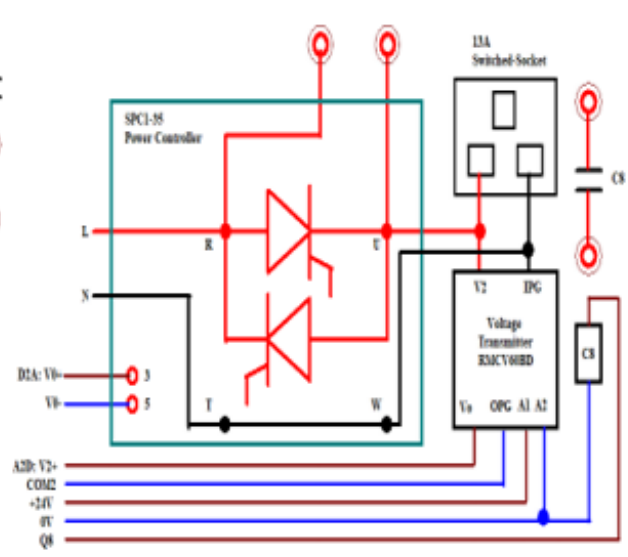

(d)

Fig 2. Wiring details of the platform.

\subsection{The Software Part}

The three-python programmed personal computers (PCs) and the programmable logic controller (PLC) share this part. Each PC is a Modbus TCP/IP client and plays the role of HMI, whereas the PLC is their Modbus TCP/IP server. 


\subsubsection{The WxPython Based Graphical User Interfaces}

The proposed platform allocates one interfacing screen for each setup. Fig 3 represents that of the three-phase induction motor starting setup. Through this screen, the user can start the motor under direct -online and star-delta starting. The starting mode selection is done via the menu labelled "Mode of Operation". The display labelled menu enables the real-time monitoring of the motor line current or displays the motor line current history. The ON /OFF commands are issued using "Start and Stop "for the Star-delta mode and "Main", "Star", and "Delta" for the direct-on-line mode of operation. The sampling time is user-defined, and this affects the recorded details of the current.

Fig 4 is the interfacing screen of the solid-state AC line controller (phase angle controller or power controller). Its "operation Mode" menu allows the user to select one of the supported modes represented by ON/OFF, Integral Cycle, phase angle, and soft starter control modes in addition to the independent switching of the magnetic contactor mode. The display labelled menu allows the real-time monitoring or displaying the history of the r.m.s value of the output voltage. This screen also gives an opportunity to the user to test different values for the ramp time ( for soft starting mode), ON and OFF periods (for the integral cycle mode), and the firing angle (for phase angle mode).

Fig 5 is the screenshot of the IDMT overcurrent setup interfacing screen. Through its "IDMT Characteristics" labelled menu, this interfacing screen allows the user to run this setup under different standard characteristic curves (IEC Normal Inverse, IEC Very Inverse, IEC Extremely Inverse, IEEE Moderately Inverse, IEEE Very Inverse, IEEE Extremely Inverse). This screen involves two input boxes to set the Time Multiplier Setting (TMS), the pickup current (Is), 4 set switches ( the green coloured), and 4 reset switches (the red coloured).

\subsubsection{The PLC as a Modbus Server}

The PLC as a Modbus device can be used as a client or server. In this work, it has been used as a server whereas the PCs take the roles of clients. The PCs as clients can do the following with the PLC:

- $\quad$ Read and write the PLC digital outputs as single or multiple

- $\quad$ Read the PLC digital inputs.

- $\quad$ Read the PLC storage memory as 16-bit register(s)

- Write the PLC storage memory as 16-bit register(s)

The read/write processes are executed for the server Modbus memory area. In PLC, this area can be configured by the programmer. In this work, the PLC Modbus memory setting is as shown in Table 1, and this means the three PCs will communicate with the PLC within this setting. They can read the PLC discrete inputs and outputs (coils), can write the PLC discrete outputs, can read the PLC memory words starting from \% MW0, and can write the PLC memory words starting from \%MW100 which is treated as register number 0 in the write registers commands. Table 2 details how the current three clients share this memory setting and command the PLC. 
Three Phase IM Direct and Star / Delta Starting

file Mode of Operation Display

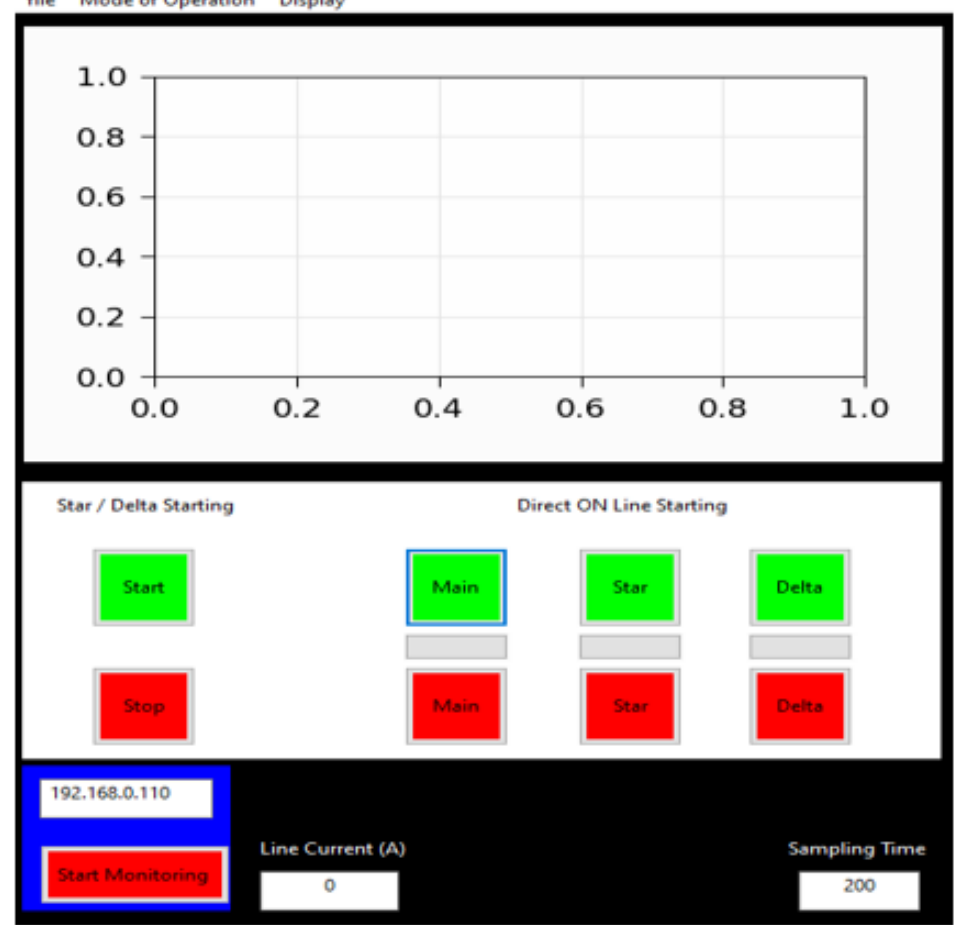

Fig 3. Induction motor startin setup inerfacing screen.

Power Controller and Magnetic Contacto

file Operation Mode Display

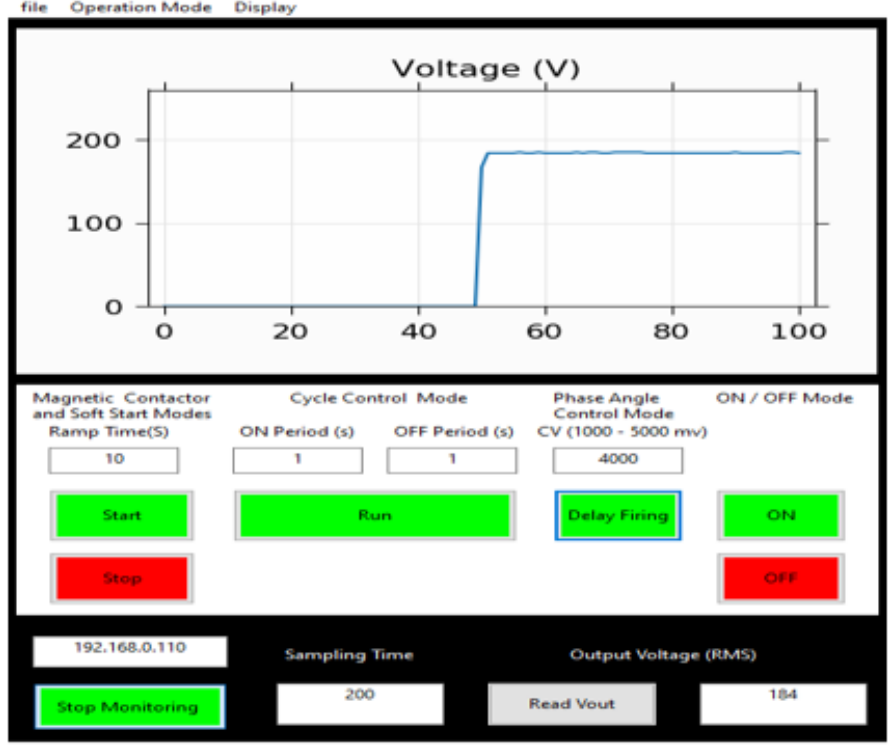

Fig 4. Solid-state AC line controller inerfacing screen. 


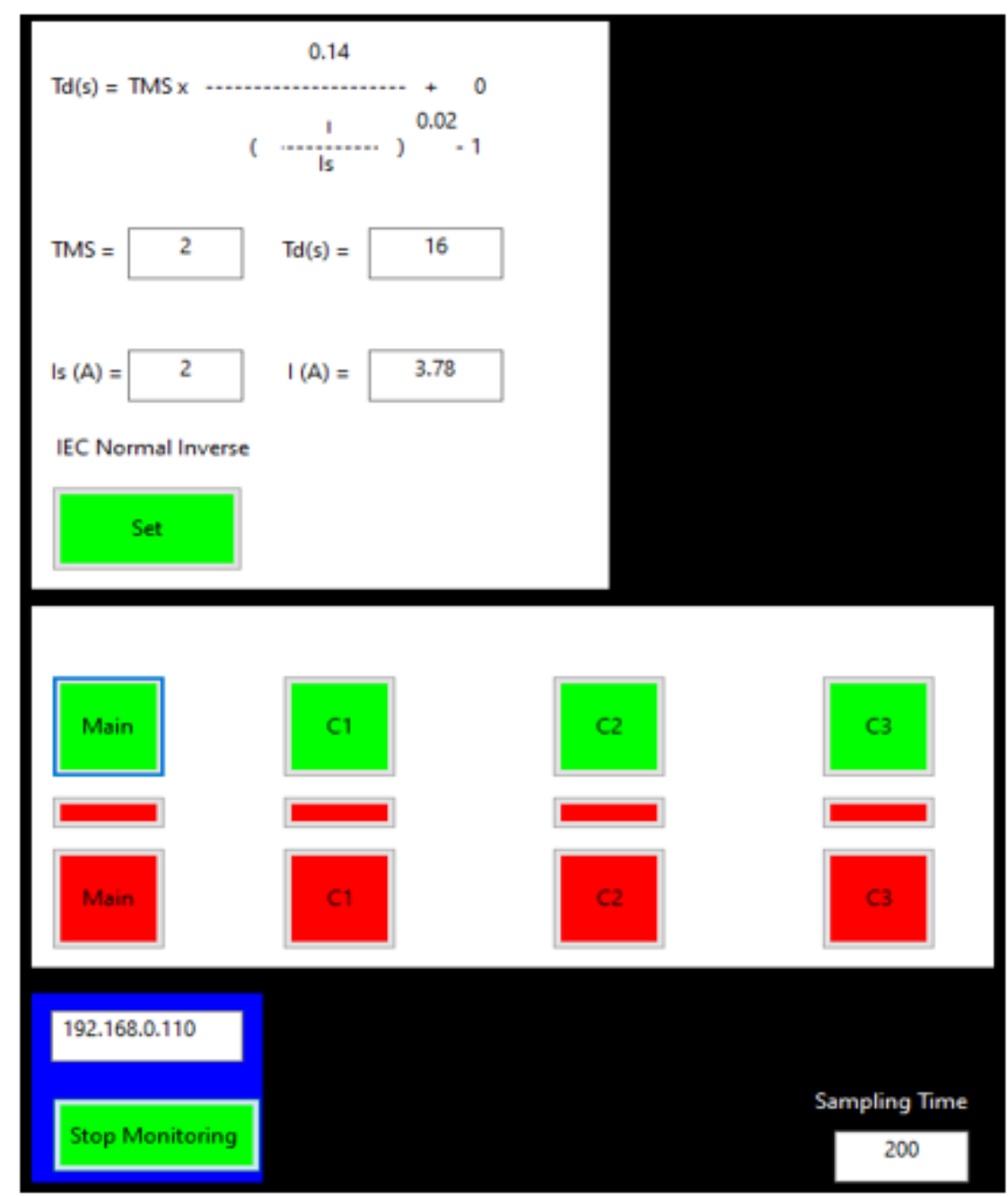

Fig 5. IDMT over current relay inerfacing screen.

Table 1. PLC Modbus Memory Setting.

\begin{tabular}{|l|l|}
\hline Bit Read Area Address & $\% \mathrm{IX0.0.0}$ \\
\hline Bit Write Area Address & $\% \mathrm{QX0.0.0}$ \\
\hline Word Read Area Address & $\% \mathrm{MW0}$ \\
\hline Word Write Area Address & $\% \mathrm{MW100}$ \\
\hline
\end{tabular}


Table 2. Modbus memory Map.

\begin{tabular}{|c|c|c|c|c|c|}
\hline \multirow[t]{2}{*}{ Setup } & \multicolumn{3}{|c|}{ Client Command } & \multirow[t]{2}{*}{ PLC Memory } & \multirow[t]{2}{*}{ Comments } \\
\hline & Address(s & Type & $\begin{array}{l}\text { Valu } \\
e^{-}\end{array}$ & & \\
\hline \multirow[t]{4}{*}{ IM Starting } & 1 & $\begin{array}{l}\text { Write } \\
\text { register }\end{array}$ & $\mathrm{X}$ & $\% \mathrm{MW} 101$ & $\begin{array}{l}X=1: \quad \text { Enable } \quad \text { DOL } \\
\text { starting, } \quad X=2: \quad \text { Start } \\
\text { YD starter, } X=3: \text { Stop } \\
\text { YD starter }\end{array}$ \\
\hline & $\mathrm{X}$ & Write coil & $\bar{Y}$ & $\% \mathrm{QX0.0.X}$ & $\begin{array}{l}\mathrm{X}=9: \mathrm{Q} 9=\mathrm{Y}, \mathrm{X}=10: \\
\mathrm{QA}=\mathrm{Y}, \mathrm{X}=\mathrm{B}: \mathrm{QC}=\mathrm{Y}\end{array}$ \\
\hline & {$[9,10,11]$} & Read coils & & $\begin{array}{l}\text { \%QX0.0.9, QX0.0.A, } \\
\% \text { QX0.0.B }\end{array}$ & $\begin{array}{l}\text { Read the status of } \mathrm{Q} 9 \\
\text { to } \mathrm{QB}\end{array}$ \\
\hline & 10 & $\begin{array}{l}\text { Read Input } \\
\text { registers }\end{array}$ & & $\% \mathrm{MW} 10$ & $\begin{array}{l}\text { Read line current } \\
(\mathrm{MW} 10=\mathrm{UW} 0.1 .3)\end{array}$ \\
\hline \multirow{7}{*}{$\begin{array}{l}\text { Phase angle } \\
\text { controller }\end{array}$} & 2 & $\begin{array}{l}\text { Write } \\
\text { registers }\end{array}$ & $\mathrm{X}$ & $\% \mathrm{MW} 102$ & $\begin{array}{l}\mathrm{X}=1: \mathrm{Q} 8=1, \mathrm{X}=2: \mathrm{Q} 8 \\
=0 ;\end{array}$ \\
\hline & 170 & $\begin{array}{l}\text { Write } \\
\text { registers }\end{array}$ & ramp & $\%$ MW270 & $\begin{array}{l}\text { To set the soft starting } \\
\text { period }\end{array}$ \\
\hline & 159 & $\begin{array}{l}\text { Write } \\
\text { registers }\end{array}$ & $\mathrm{X}$ & $\% \mathrm{MW} 259$ & $\begin{array}{l}\text { Set the operation } \\
\text { mode: } X=1 \text { to } 5\end{array}$ \\
\hline & 160 & $\begin{array}{l}\text { Write } \\
\text { registers }\end{array}$ & $\mathrm{X}$ & $\% \mathrm{MW} 260$ & $\begin{array}{l}\text { Apply } 5 * X \text { volt for } \\
\text { the controller }(X=1 \text { or } \\
0)\end{array}$ \\
\hline & 60 & $\begin{array}{l}\text { Read input } \\
\text { registers }\end{array}$ & & $\% \mathrm{MW60}$ & $\begin{array}{l}\begin{array}{l}\text { Read the controller } \\
\text { output voltage }\end{array} \\
\text { MW60(MW60= } \\
\text { UW0.1.4)/48) }\end{array}$ \\
\hline & $\begin{array}{l}{[161,162,1} \\
63]\end{array}$ & $\begin{array}{l}\text { Write } \\
\text { registers }\end{array}$ & $\begin{array}{l}\mathrm{A}, \mathrm{B} \\
\mathrm{C}\end{array}$ & $\begin{array}{l}\text { \%MW261,\%MW262, } \\
\text { \%MW263 }\end{array}$ & $\begin{array}{l}\text { A to enable \& disable } \\
\text { the cycle mode, B \& } \\
\mathrm{C} \text { set the mark and } \\
\text { space periods. }\end{array}$ \\
\hline & 164 & $\begin{array}{l}\text { Write } \\
\text { registers }\end{array}$ & alpha & $\%$ MW264 & $\begin{array}{l}\text { Set the firing angle } \\
\text { equivalent value }\end{array}$ \\
\hline \multirow{3}{*}{$\begin{array}{l}\text { IDMT } \\
\text { relay }\end{array}$} & {$[131,132]$} & $\begin{array}{l}\text { Write } \\
\text { registers }\end{array}$ & $\begin{array}{l}\text { Is, } \\
\text { TMS }\end{array}$ & \%MW231,\%MW232 & $\begin{array}{l}\text { Set the pickup and } \\
\text { TMS values }\end{array}$ \\
\hline & 130 & $\begin{array}{l}\text { Write } \\
\text { registers }\end{array}$ & $\mathrm{X}$ & $\% \mathrm{MW} 230$ & $\begin{array}{l}\text { Set the characteristic } \\
\text { curve type }(X=0 \text { to } 5)\end{array}$ \\
\hline & $\mathrm{X}$ & Write coil & $\mathrm{Y}$ & $\%$ QX0.0.X & $\begin{array}{l}\mathrm{X}=0 \text { : Main, } \mathrm{X}=1: \mathrm{C} 1 \text {, } \\
\mathrm{X}=2: \quad \mathrm{C} 2, \quad \mathrm{X}=3 \text { : } \mathrm{C} 3 \\
\text { magnet contactor }\end{array}$ \\
\hline
\end{tabular}

\section{Discussion}

The proposed platform allows three students groups to share one PLC to operate three experimental setups at the same time. Each setup allows the students to experimentally understand or verify certain topics of the classroom as follow: 


\subsection{Three Phase Induction Motor Starting Setup}

With this setup, the students can sense the difference between direct-on-line and start delta starting. Fig 6 is a snapshot of the recorded motor line current data under star connection, delta connection, and star-start delta-run connection. As it is evident from the figure, this setup and through its recording facility can clearly show the students why a star-delta starter is necessary. This response belongs to a three-phase squirrel cage induction motor with a $3.0 \mathrm{~A}$ full load current. With direct delta starting this motor draw about two times its rated current whereas with star-delta starter draw slightly more than its rated current.

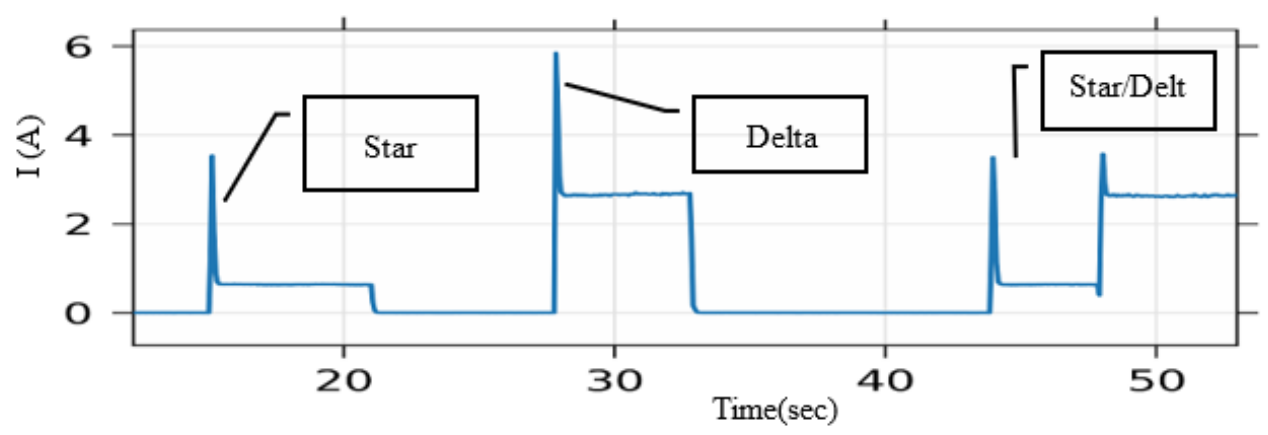

Fig 6. $3 \mathrm{Ph}$ IM starting current under Star, Delta , \& Star/Delta starting.

\subsection{Single Phase AC Line Controller Setup}

A single-phase AC line controller (power controller) consists of two anti-parallel connected thyristors. Industrially, AC line controllers are widely used with heating elements. These power electronic elements use an analogy signal to determine the firing delay to the zero crossing instants of the applied voltage. This structure allows these elements to be run in a different mode of operation like ON/OFF, Phase angle, and Integral Cycle control mode of operations. With this setup, the students have an opportunity to explore the physical meaning of each of these supported modes and to understand the difference between the magnetic contactor and AC line controller. Figs 7 to 9 are snapshots for the recorded data of the r.m.s values of the output voltage of the ac line controller under different modes. Fig 7 shows the operation of this device under cycle mode of operation in which the analogue control signal input terminal receives either its minimum value for the OFF state or maximum value for the ON state and the ON/OFF is cyclic. Fig 8 shows the difference between the ac line controller as a solid-state relay and the magnetic contactor. With ac line controller, the forward voltage drop across the thyristors is clear whereas there is no voltage drop in the case of the magnetic contactor. In Fig 9, the analogue control signal has been gradually increased from its minimum to its maximum values. This mode of operation is used for soft starting. With this setup which consists of a single-phase ac line controller, magnetic contactor, and r.m.s value voltage transmitter, the students can be introduced to the soft starting concept. Fig 9 shows the soft starting under two ramp slops, (a) belongs to $1 \mathrm{sec}$ and (b) belongs to $10 \mathrm{sec}$. Table 3 lists the relation between the analogue control voltage setting, and the PLC digital to the analogue voltage applied to the controller analogue input control terminal 
and the r.m.s value of the output voltage of the controller. As it is seen, the control voltage setting is the mv picture of the real voltage applied to the ac controller control terminal. Through this utility, the students can get an experimental idea about the relation between the control voltage setting and the output voltage r.m.s value as illustrated in Fig 10.

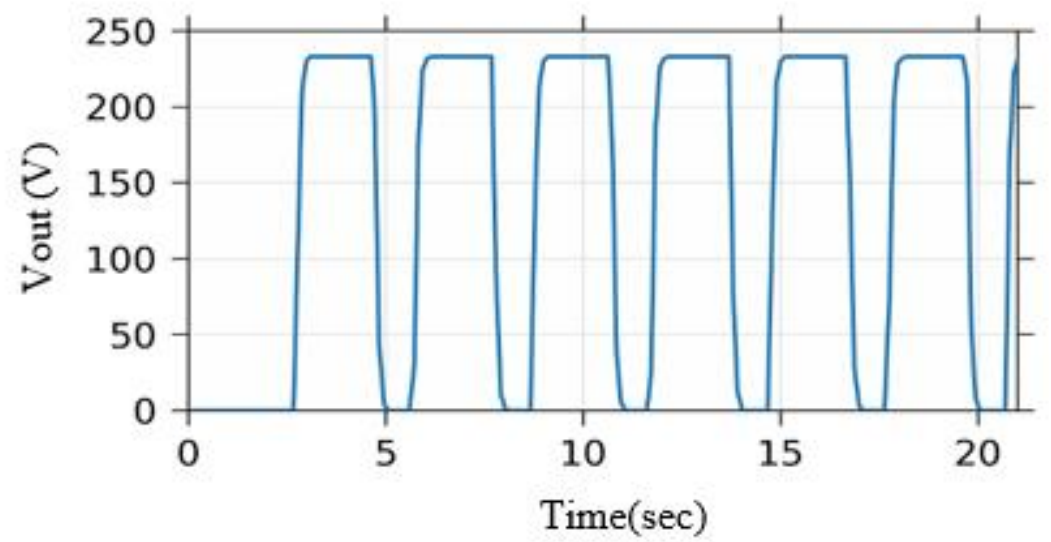

Fig 7. Controller output voltage under cycle mode.

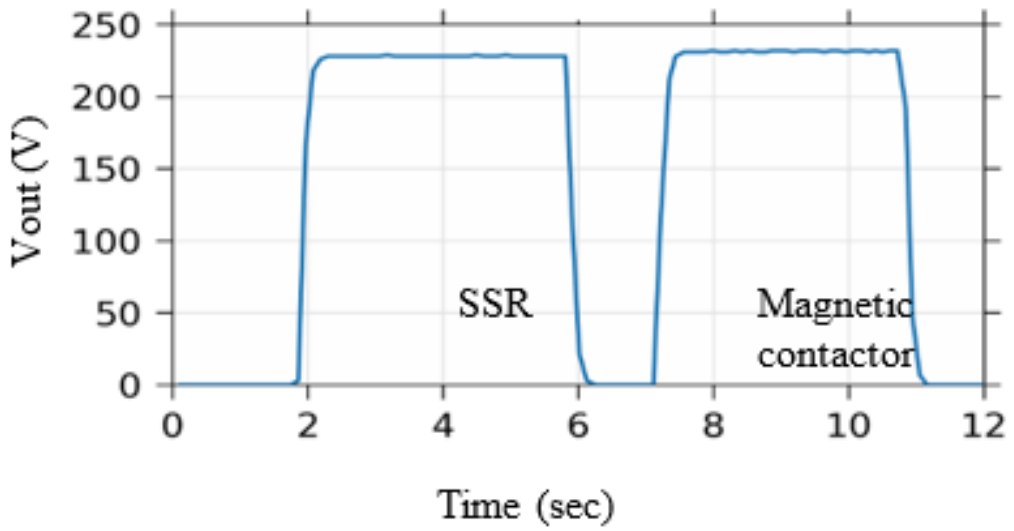

Fig 8. Controller output voltage with bypass contact. 


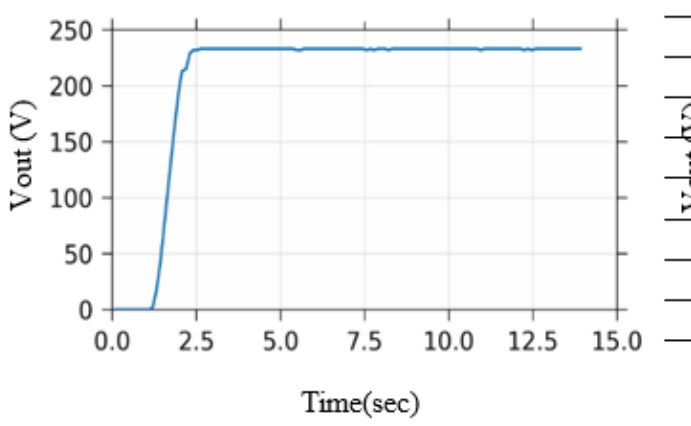

(a)

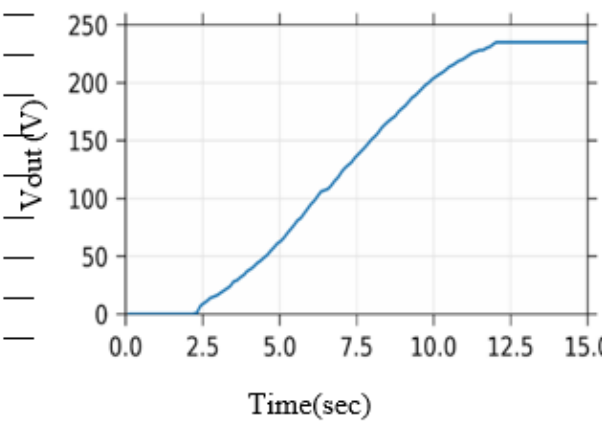

(b)

Fig 9. Controller output voltage under soft start mode. (a): $1 \mathrm{sec}$ ramp period. (b): $10 \mathrm{sec}$ ramp period.

Table 3. The relation between the analogue control voltage setting and the PLC digital to the analogue voltage applied to the controller analogue input control terminal

\begin{tabular}{|c|c|c|}
\hline Analog Voltage user setting & Analog Voltage & R.M.S of Vout (V) \\
\hline 1000 & 1.200 & 0 \\
\hline 1500 & 1.503 & 11 \\
\hline 2000 & 2.005 & 37 \\
\hline 2500 & 2.506 & 70 \\
\hline 3000 & 3.007 & 112 \\
\hline 3500 & 3.508 & 149 \\
\hline 4000 & 4.000 & 184 \\
\hline 4500 & 4.510 & 213 \\
\hline 5000 & 5.010 & 227 \\
\hline
\end{tabular}




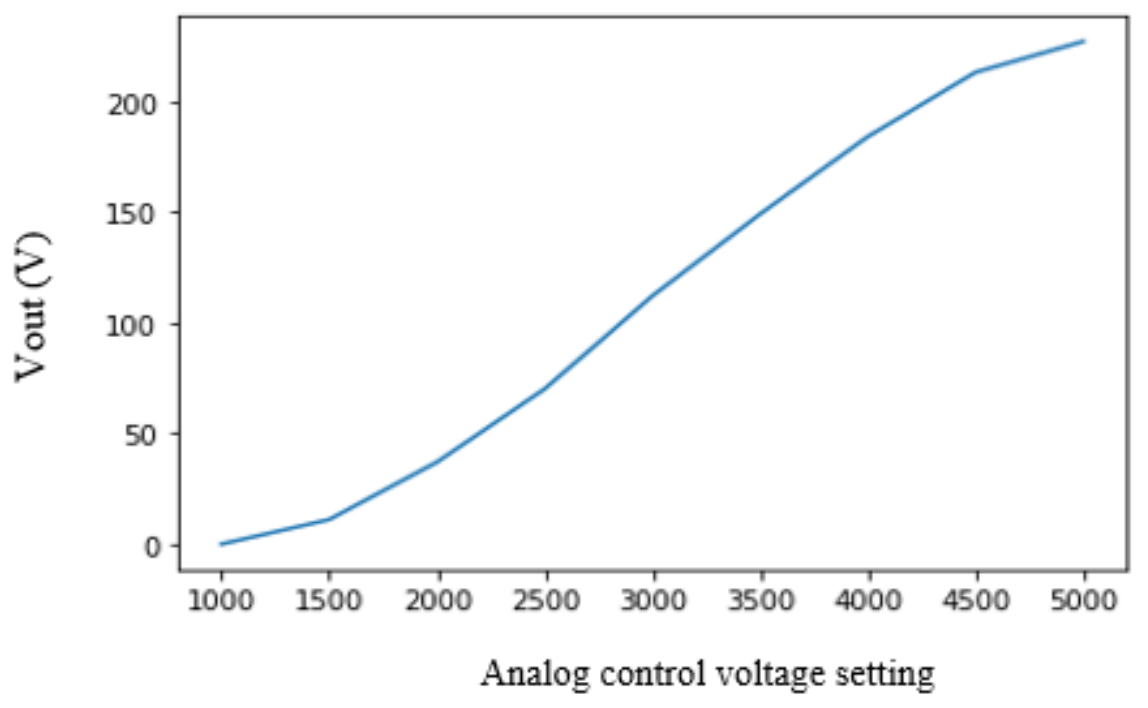

Fig 10. Control voltage setting versis Vout

\subsection{IDMT Overcurrent Relay Setup}

An inverse definite minimum time (IDMT) overcurrent relays are widely used in the protection of electrical equipment. The IDMT over-current relay characteristic is represented as in equation (1) [12]:

$\mathrm{T}=\operatorname{TMS} \times\left\{\left[\frac{\mathrm{k}}{\left(\frac{\mathrm{I}}{\mathrm{I}_{\mathrm{s}}}\right)^{\mathrm{a}}-1}\right]\right\}+\mathrm{c}$

With this platform, the students can sense the effect of the IDMT 's parameters ( $k$, a, and c) on the tripping delay time in addition to the effect of the time multiplier setting (TMS). Table 4 shows the setup's outcome for different plug settings for the six standard characteristic curves.

Table 4. Trip delay time in sec.

\begin{tabular}{|l|l|l|l|l|l|l|l|l|l|}
\hline \multirow{2}{*}{ Curve Type } & \multicolumn{9}{|c|}{ Plug Setting } \\
\cline { 2 - 10 } & 1 & 1.25 & 1.5 & 1.75 & 2 & 2.25 & 2.5 & 2.75 & 3 \\
\hline $\begin{array}{l}\text { IEC normal } \\
\text { Inverse }\end{array}$ & $\infty$ & 32 & 17 & 12 & 10 & 08 & 07 & 07 & 06 \\
\hline $\begin{array}{l}\text { IEC Very } \\
\text { Inverse }\end{array}$ & $\infty$ & 56 & 27 & 18 & 13 & 10 & 09 & 07 & 07 \\
\hline $\begin{array}{l}\text { IEC Extremely } \\
\text { Inverse }\end{array}$ & $\infty$ & 53 & 24 & 15 & 10 & 07 & 06 & 04 & 04 \\
\hline $\begin{array}{l}\text { IEEE Moderately } \\
\text { Inverse }\end{array}$ & $\infty$ & 12 & 06 & 05 & 04 & 03 & 03 & 03 & 02 \\
\hline IEEE Very & $\infty$ & 35 & 16 & 10 & 07 & 05 & 04 & 03 & 03 \\
\hline
\end{tabular}




\begin{tabular}{|l|l|l|l|l|l|l|l|l|l|}
\hline Inverse & & & & & & & & & \\
\hline $\begin{array}{l}\text { IEEE Extremely } \\
\text { Inverse }\end{array}$ & $\infty$ & 50 & 22 & 14 & 09 & 07 & 05 & 04 & 04 \\
\hline
\end{tabular}

\section{Conclusions}

In this paper, a PC/PLC-based platform for the simultaneous running of three laboratory experimental setups (using WxPython and Pymodbus) has been presented. The currently supported setups are three-phase induction motor starting, single-phase ac line controller and IDMT overcurrent relay setups. The platform offers an experimental opportunity to sense the undesirable value of the three-phase induction motor starting current under direct-on-line starting and compare the drawn current with that under star connection, understand the various operating mode of the single-phase ac line controller and the difference with the magnetic relay in addition to its cooperation with the magnetic contactor to construct soft starter, provide a cost-effective platform for understanding the overcurrent protective relays and their behaviour under different characteristic curve settings. The platform also offers real-time monitoring and history recording facilities. The real-time monitory facility functions as if it were an oscilloscope. The history recording facility allows the user to come across every instant in the operation journey of the setup under consideration. Through the history recording facility, the motor starting current can be seen as a situation that is difficult to be sensed by the traditional metering facilities. The overall cost can be highly reduced by using cheap second-hand PCs as clients.

\section{References}

[1] Trevelyan, J.P. Technical Coordination in Engineering Practice. Journal of Engineering Education, 2007. 96 (3): pp. 191-204.

[2] Luo Y., Jeevjyot Singh Chhabda J. S. Design and Implementation of a Virtual Lab in an Engineering Laboratory Course, $54^{\text {th }}$ ASC Annual International Conference Proceeding (2018).

[3] Razali Z. B. and Trevelyan J. Valuable Experience in Engineering Laboratory: Enhance Understanding of Engineering Concepts. Regional Conference on Engineering Education (RCEE 2007).

[4] Rashid M., Imran A. T., Zia Y. I., Al-Turkistany M., and Rashid S. Evaluation of Engineering Laboratories. International Conference on Education and e-Learning Innovations (2012).

[5] Norrie S. E. The role of laboratory work in engineering education: student and staff perceptions. International journal of Electrical Engineering Education (2016).

[6] Al Mashhadany Y. I. Design and Implement of a Programmable Logic Controller (PLC) for Classical Control Laboratory. Intelligent Control and Automation, 2012, 3, pp. 44-49.

[7] Fernandes J.M. and Van N. T. A Programmable Logic Controller Based Laboratory: Analysis of Conventional and Intelligent Control Schemes for on linear Systems. Journal for New Generation Sciences, Volume 13 Number 3, 2015. 
[8] Mahmood J. R., Ali R. S., Migdadi H., Abd-Alhameed R. A. and Ibrahim, E.M. Development of Educational Fuzzy Control Laboratory Using PLC, and HMI. In Proceedings of the Internet Technologies and Applications Conference (ITA15), Wrexham, UK, 8-11 September 2015; pp. 383387.

[9] Geaney G. and O'Mahoney T. Design and evaluation of a remote PLC laboratory. The International Journal of Electrical Engineering and Education (2015).

[10] Ozerdem O. C. Design of two experimental setups for programmable logic controller (PLC) laboratory. International Journal of Electrical Engineering Education (2016).

[11] Alves L.F., Brandao D. and Oliveira A. A multi-process pilot plant as a didactical tool for the teaching of industrial processes control in electrical engineering course. International Journal of Electrical Engineering Education (2018).

[12] Mahmood J. R., Ali R. S., and Abd-Alhameed R. A. PLC/HMI-Based Implementation of a RealTime Educational Power System Protective Relays Platform. electronics, MDPI, 2020, 9 (1), 118.

[13] Ryan E., Mohammed A. A review on applications of programmable logic controller. 2016, Renewable and sustainable energy reviews.

[14] Jeong Y., Ansari M. I., Shin W., Kang B., Lim J., Moon H., and Shim J. PLC and Arduino Interaction Based on Modbus Protovol. Journal of Korea Multimedia Society Vol.20, No.3, March 2017, pp. 511-519.

[15] John Hunt J. A Beginners Guide to Python 3 Programming. Springer Nature Switzerland AG 2019.

[16] PyModbus Documentation, Release 2.5.0 2021.

[17] Mehta K., Joshi R., Jadav H. M., and Kulkarni S. V. Integration of MODBUS/TCP master monitoring and control system using python for High power RF system. Conference: International Conference on Electrical, Electronics, Signals, Communication and Optimization (EESCO) - 2015. 